\title{
RIFLE criteria for acute kidney injury in aortic arch surgery
}

George J. Arnaoutakis, MD, ${ }^{a}$ Azra Bihorac, MD, ${ }^{\mathrm{b}}$ Tomas D. Martin, MD, ${ }^{a}$ Philip J. Hess, Jr, MD, ${ }^{\text {a }}$ Charles T. Klodell, MD, A. Ahsan Ejaz, MD, ${ }^{c}$ Cyndi Garvan, PhD, ${ }^{d}$ Curtis G. Tribble, MD, ${ }^{a}$ and Thomas M. Beaver, MD, MPH ${ }^{a}$

From the Divisions of Thoracic and Cardiovascular Surgery, ${ }^{\text {a }}$ Critical Care Medicine, ${ }^{\mathrm{b}}$ Nephrology, ${ }^{\mathrm{c}}$ and Biostatistics, ${ }^{\mathrm{d}}$ University of Florida, Gainesville, Fla.

The RIFLE criteria, an international definition for AKI, were used in a retrospective study of patients undergoing aortic surgery. Predictors for AKI were hypertension, CKD, pRBCs greater than 5 units, and a higher than predicted admission creatinine; predictors for mortality were age, AKI by RIFLE, and CVA.

Read at the Eighty-seventh Annual Meeting of The American Association for Thoracic Surgery, Washington, DC, May 5-9, 2007.

Received for publication May 4, 2007; revisions received Aug 7, 2007; accepted for publication Aug 15, 2007.

Address for reprints: Thomas M. Beaver, MD, MPH, Associate Professor, Division of Thoracic and Cardiovascular Surgery, University of Florida, PO Box 100286, Gainesville, FL 32610-0286 (E-mail: beavetm@surgery.ufl.edu).

J Thorac Cardiovasc Surg 2007;134:1554-61 $0022-5223 / \$ 32.00$

Copyright (C) 2007 by The American Association for Thoracic Surgery

doi:10.1016/j.jtcvs.2007.08.039
Objective: The RIFLE criteria are new international consensus definitions for acute kidney injury introduced to facilitate research across disciplines. We identified risk factors for acute kidney injury, renal replacement therapy, and mortality using the RIFLE criteria (RIFLE $=$ risk, $i$ jury, failure, loss, $e$ nd stage) in patients undergoing deep hypothermic circulatory arrest for aortic arch reconstruction.

Methods: A single-center retrospective cohort study of 267 patients undergoing aortic arch surgery with deep hypothermic circulatory arrest was conducted between July 2001 and October 2005. Known predictors (age, chronic kidney disease, surgery status, redo, diabetes, hypertension, blood transfusion, bypass, and deep hypothermic circulatory arrest time) were used in multivariate logistic regression models for acute kidney injury, renal replacement therapy, and mortality.

Results: Mean age was 64 years (range 23-89 years) with 166 men (62\%). Seventy-five (28\%) had RIFLE scores of I or F, and $22(8 \%)$ required dialysis. Risk factors for acute kidney injury were hypertension (odds ratio $[\mathrm{OR}]=2.17 ; 95 \%$ confidence intervals $[\mathrm{CI}], 1.14-4.15)$, chronic kidney disease $(\mathrm{OR}=9.04 ; 95 \% \mathrm{CI}$, 1.97-41.59), packed red blood cells greater than 5 units ( $\mathrm{OR}=2.37$; $95 \% \mathrm{CI}$, 1.20-4.69), and admission creatinine/Modification of Diet in Renal Disease predicted creatinine ratio greater than $1(\mathrm{OR}=3.54 ; 95 \% \mathrm{CI}, 1.95-6.45)$. Risk factors for mortality were age (per 10 years) $(\mathrm{OR}=2.35$; 95\% CI, 1.35-4.06), AKI (RIFLE class $\mathrm{R}$, I, or F) (OR $=4.60$; 95\% CI, 1.34-15.77), and cerebrovascular accident $(\mathrm{OR}=19.1 ; 95 \% \mathrm{CI}, 4.96-73.58)$. Mortality increased with each RIFLE stratification (RIFLE class $0=3 \%, \mathrm{R}=9 \%, \mathrm{I}=12 \%$, and $\mathrm{F}=38 \%$ ).

Conclusions: Acute kidney injury as defined according to the RIFLE classification is a risk factor for mortality and will be useful in future studies of renal dysfunction in thoracic aortic surgery.

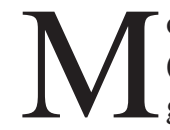
ore than 30 years have elapsed since deep hypothermic circulatory arrest (DHCA) was introduced for cerebral protection during aortic arch surgery. ${ }^{1}$ Improved surgical and anesthetic techniques have facilitated increasingly complex aortic reconstructions with decreased morbidity and mortality. ${ }^{2-4}$ However, postoperative acute kidney injury (AKI) remains a significant problem in the setting of DHCA, with an incidence ranging from $8 \%$ to $50 \%$, although various definitions have been used.$^{5-7}$ Renal dysfunction leads to increased postoperative morbidity and mortality, and patients requiring renal replacement therapy (RRT) have mortality as high as $64 \% .^{2,8-13}$

Several studies have examined AKI after DHCA, with multiple definitions including the following: $50 \%$ increase in serum creatinine above baseline $e^{5,14} ; 25 \%$ reduction in calculated creatinine clearance ${ }^{6}$; and need for dialysis. ${ }^{15}$ The variety of definitions hinders comparison between studies of kidney injury. ${ }^{14}$ Accordingly, the Acute Dialysis Quality Initiative Workgroup set forth a new international consensus definition for renal injury (RIFLE criteria), which stratifies renal failure into three grades of increasing severity of acute kidney injury $(\mathrm{R}=$ risk, $\mathrm{I}=$ injury, $\mathrm{F}=$ 


\author{
Abbreviations and Acronyms \\ AKI = acute kidney injury \\ CI = confidence interval \\ $\mathrm{CKD}=$ chronic kidney disease \\ $\mathrm{CPB}=$ cardiopulmonary bypass \\ CVA = cerebrovascular accident \\ DHCA $=$ deep hypothermic circulatory arrest \\ GFR = glomerular filtration rate \\ MDRD $=$ Modification of Diet in Renal Disease \\ $\mathrm{OR}=$ odds ratio \\ $\mathrm{PRBCs}=$ packed red blood cells \\ RIFLE = risk, injury, failure, loss, end stage kidney \\ disease \\ RRT = renal replacement therapy
}

failure) and two outcome classes $(\mathrm{L}=$ loss, and $\mathrm{E}=$ end-stage kidney disease) (Table 1). The three grades of severity for AKI are based on changes in either serum creatinine or urine output from baseline. ${ }^{16}$

The RIFLE criteria previously have been validated in patients undergoing coronary artery bypass and valve surgery. ${ }^{17}$ However, in that patient population the incidence of renal dysfunction was low with only $8.5 \%$ of patients meeting criteria for I or $\mathrm{F}$ classification. The purpose of this study is to validate the RIFLE criteria as a classification scheme for AKI in a more homogeneous group of patients undergoing DHCA for aortic arch surgery, in which there is a higher incidence of renal injury. Multivariate analysis was performed to identify risk factors for postoperative kidney injury and mortality using the new RIFLE criteria.

\section{Patients and Methods}

After Institutional Review Board approval, the medical records of patients undergoing thoracic aortic surgery at Shands Hospital at the University of Florida between July 2001 and October 2005 were retrospectively reviewed. During this period, 281 patients required DHCA for operations involving the aortic arch, and they comprise the cohort for the present analysis. Patients who died intraoperatively were excluded, inasmuch as no change in renal function could be identified. It should be noted that patients with a history of advanced chronic kidney disease (CKD stage 4 with estimated glomerular filtration rate [GFR] $<30 \mathrm{ml}$. $\min ^{-1} \cdot 1.73 \mathrm{~m}^{-2}$ ) or CKD stage 5 (long-term RRT) were also excluded. The rationale for this exclusion was that it is already known that patients with severe kidney disease defined as CKD stage 4 or 5 are already on or will progress to RRT and have poor outcomes. ${ }^{18}$ Patients with CKD stages 1 to 3 with or without AKI were included in the analysis inasmuch as the emphasis was to evaluate these patients with either preoperative normal renal function or only mild-to-moderate impairment. In total, 14 patients were excluded; therefore 267 patients were included in the RIFLE analysis.

Demographic and operative variables previously reported to be associated with postoperative renal dysfunction were compiled into the cardiac surgery database, which was managed by an experienced research nurse. ${ }^{19,20}$ Demographic variables included age, gender, previous history of diabetes mellitus, hypertension (defined as patients with a documented history of hypertension previously being treated with an antihypertensive agent), cerebrovascular disease (defined by history of stroke or transient ischemic attack or known carotid occlusive disease $>50 \%$ ), peripheral vascular disease, and chronic obstructive pulmonary disease; predicted serum creatinine according to the Modification of Diet in Renal Disease (MDRD) formula, ${ }^{21}$ history of CKD (defined above), primary operation versus reoperation ("redo"), use of aprotinin (Trasylol; Bayer, West Haven, Conn) or epsilon aminocaproic acid (Amicar; Xanodyne, Florence, Ky), and surgical status (elective versus emergency). Operative variables measured were: cardiopulmonary bypass (CPB) time, aortic crossclamp time, DHCA time, and need for more than 5 units of packed red blood cells (pRBCs) intraoperatively and/or first 7 days postoperatively. Patients were classified according to the maximum RIFLE $\left(\right.$ RIFLE $_{\max }$ ) class (risk $=\mathrm{R}$, injury $=\mathrm{I}$, or failure $=F$ ) reached during the first 7 days after the operation. The RIFLE class was determined on the basis of the lowest GFR criteria by using the change in serum creatinine levels (Table 1). ${ }^{17}$

TABLE 1. Description of the RIFLE system in acute renal failure

\begin{tabular}{llc}
\hline & \multicolumn{1}{c}{ GFR criteria } & Urine output criteria \\
\hline Risk & Plasma creatinine increase $1.5 \times$ baseline or GFR decline $>25 \%$ & $<0.5 \mathrm{~mL} \cdot \mathrm{kg}^{-1} \cdot \mathrm{h}^{-1} \times 6 \mathrm{~h}$ \\
Injury & Plasma creatinine increase $2 \times$ baseline or GFR decline $>50 \%$ & $<0.5 \mathrm{~mL} \cdot \mathrm{kg}^{-1} \cdot \mathrm{h}^{-1} \times 12 \mathrm{~h}$ \\
Failure & Plasma creatinine increase $3 \times$ baseline or GFR decline $>75 \%$ & $<0.3 \mathrm{~mL} \cdot \mathrm{kg}^{-1} \cdot \mathrm{h}^{-1} \times 24 \mathrm{~h}$ \\
& or acute plasma creatinine $>4 \mathrm{mg} / \mathrm{dL}$ & anuria $\times 12 \mathrm{~h}$ \\
Loss & Persistent ARF $=$ complete loss of kidney function requiring \\
End stage & dialysis for $>4$ wk but $<3$ mo & \\
\hline
\end{tabular}

GFR, Glomerular filtration rate; ARF, acute renal failure. 


\section{End Points}

The primary outcomes analyzed were AKI, need for postoperative RRT, and in-hospital mortality. Need for reoperation during the same hospitalization and postoperative cerebrovascular accident (CVA) as determined by a formal neurologic evaluation were recorded as well.

\section{Operative Procedure}

Elective ascending and aortic arch operations were performed through a standard median sternotomy with dualstage venous cannulation of the right atrium. Epiaortic scanning was used in ascending aortic aneurysms before aortic cannulation to confirm the absence of mural thrombus or calcification. Acute ascending aortic dissections were cannulated via an axillary or femoral artery. Before cannulation, heparin was administered (350 IU/kg). CPB was initiated only after assuring kaolin-activated clotting times were greater than 480 seconds. Almost all patients received aprotinin, typically "full dose" $\left(2 \times 10^{6}\right.$ units intravenous load, $2 \times 10^{6}$ units in the pump prime, and $5 \times 10^{5}$ units/h); a minority of patients in our early experience received epsilon aminocaproic acid. Cardioplegic arrest was obtained with handheld antegrade cardioplegia catheters in the coronary ostia and with retrograde cardioplegia catheters in the coronary sinus; cardioplegic solution was redosed at 20minute intervals via the retrograde catheter. Patients were monitored with cerebral oximetry and intraoperative electroencephalography. Temperature monitoring included nasopharyngeal, rectal, and bladder probes. Circulatory arrest was initiated after confirming no cerebral activity on the electroencephalogram with nasopharyngeal temperature at $18^{\circ} \mathrm{C}$. Retrograde cerebral perfusion via a snared superior vena cava cannula was used when circulatory arrest times were greater than 20 minutes.

\section{Data Analysis}

A trained registered nurse database manager reviewed records of demographic, intraoperative, and postoperative variables, which were subsequently assembled in our institutional Microsoft Excel database (Microsoft, Redmond, Wash). Data were then exported to Statistica for analysis (StatSoft, Inc, Tulsa, Okla). Demographic and operative variables were compared among four groups (RIFLE classes $0, \mathrm{R}, \mathrm{I}$, and $\mathrm{F}$ ) using analysis of variance and the $\chi^{2}$ or Fisher exact tests where appropriate for continuous and categorical variables, respectively. Risk factors of AKI (defined by RIFLE classes R, I, or F) were determined by univariate logistic regression. Known risk factors for renal dysfunction and univariate predictors with $P$ values $<.05$ in the present analysis were then entered into a logistic regression model to identify independent risk factors for AKI. Odds ratios (OR) and 95\% confidence intervals (CI) were calculated. The same methods were used to identify vari-
TABLE 2. Multivariate predictors for mortality

\begin{tabular}{lccc}
\hline Variable & OR & 95\% CI & $\boldsymbol{P}$ value \\
\hline AKI (all RIFLE stages) & 4.60 & $1.34-15.77$ & .01 \\
Age (per 10 years) & 2.34 & $1.35-4.06$ & $<.01$ \\
History of CAD & 2.45 & $0.79-7.63$ & .12 \\
Hypertension & 0.65 & $0.22-1.95$ & .44 \\
Redo & 0.65 & $0.18-2.41$ & .52 \\
Emergency surgery & 1.57 & $0.58-4.42$ & .39 \\
CPB time > 200 min & 1.21 & $0.36-4.01$ & .76 \\
DHCA time > 31 min & 1.33 & $0.46-3.87$ & .59 \\
pRBCs > 5 units & 1.65 & $0.51-5.38$ & .40 \\
CVA & 19.1 & $4.95-73.58$ & $<.01$ \\
Reoperation & 2.75 & $0.42-17.86$ & .29
\end{tabular}

$O R$, Odds ratio; $C l$, confidence interval; $C A D$, coronary artery disease; $C P B$, cardiopulmonary bypass; $D H C A$, deep hypothermic circulatory arrest; pRBCs, packed red blood cells; CVA, cerebrovascular accident.

ables independently associated with RRT and mortality. The model for RRT did not include AKI, as by definition all patients who require RRT are considered to be in RIFLE class $\mathrm{F}$. To determine an independent effect with regard to mortality, we incorporated AKI into the mortality logistic regression model in addition to other significant variables (Table 2).

\section{Results}

The mean age of the 267 patients was 64 years (range 23-89 years). There were 166 men (62\%), and 101 women (38\%). Comorbidities included diabetes (12\%), hypertension $(67 \%)$, coronary artery disease $(46 \%)$, cerebrovascular disease (9\%), chronic obstructive pulmonary disease (14\%), history of CKD (9\%), and peripheral vascular disease (8\%). Fifty-seven patients $(21 \%)$ underwent redo procedures, and $52(91 \%)$ of these operations were performed in an elective setting. Ninety-five patients in this series required DHCA for aortic dissection repair; of these dissections, the majority were acute aortic dissections as only 24 (25\%) were chronic in nature. Operations were performed on an emergency basis for 97 patients (36\%), and 71 of these were acute dissections. Aprotinin was administered to 239 (88.8\%), and the remainder received epsilon aminocaproic acid; these groups differed significantly only in that more patients undergoing redo operations received aprotinin. Median CPB time was 175 minutes and median DHCA time was 18 minutes. One hundred seventy-six patients underwent concomitant valvular operations and 83 required simultaneous coronary artery bypass grafting. Demographic and operative variables are depicted according to RIFLE severity grades in Table 3. Significant differences among the four groups were detected for the following variables: age, hypertension, $\mathrm{CAD}$, emergency surgery, mean $\mathrm{CPB}$ time, mean DHCA time, pRBCs greater than 5 units, and mean chest tube output. 
TABLE 3. Patient characteristics and operative variables by RIFLE classification8

\begin{tabular}{|c|c|c|c|c|c|}
\hline & RIFLE-0 (n = 138) & RIFLE-R ( $n=54)$ & RIFLE-I (n = 33) & RIFLE-F ( $n=42)$ & $P$ valuet \\
\hline \multicolumn{6}{|l|}{ Demographics } \\
\hline Age, y & 61 & 65 & 67 & 66 & .02 \\
\hline Male gender, n (\%) & $88(64)$ & $30(55)$ & $22(67)$ & $26(62)$ & .69 \\
\hline Hypertension, n (\%) & $80(58)$ & $46(85)$ & $25(76)$ & $29(69)$ & .002 \\
\hline Diabetes mellitus, $\mathrm{n}(\%)$ & $17(12)$ & $5(9)$ & $6(18)$ & $4(9)$ & .61 \\
\hline COPD, n (\%) & $16(12)$ & $7(13)$ & $6(18)$ & $9(21)$ & .38 \\
\hline CAD, n $(\%)$ & $52(38)$ & $28(52)$ & $19(58)$ & $23(55)$ & .05 \\
\hline PVD, n (\%) & $10(7)$ & $6(11)$ & $2(6)$ & $4(9)$ & .78 \\
\hline Redo status, n (\%) & $28(20)$ & $15(28)$ & $7(21)$ & $7(17)$ & .58 \\
\hline Emergency surgery, n (\%) & $43(32)$ & $14(26)$ & $15(46)$ & $25(60)$ & .01 \\
\hline \multicolumn{6}{|l|}{ Operative variables } \\
\hline Mean CPB time, min (SD) & $174(48)$ & $170(49)$ & $215(82)$ & $203(76)$ & $<.01$ \\
\hline Mean DHCA time, min (SD) & $22(15)$ & $24(16)$ & $26(17)$ & $28(15)$ & .05 \\
\hline Mean crossclamp time, $\min (S D)$ & $106(53)$ & $95(45)$ & $124(64)$ & $111(55)$ & .11 \\
\hline $\mathrm{pRBC} s>5$ units, $\mathrm{n}$ & $30(22)$ & $16(29)$ & $16(48)$ & $31(74)$ & $<.01$ \\
\hline Mean chest tube output, mL & 1149 & 1190 & 1424 & 1914 & $<.01$ \\
\hline
\end{tabular}

$C O P D$, Chronic obstructive pulmonary disease; $C A D$, coronary artery disease; $P V D$, peripheral vascular disease; $C P B$, cardiopulmonary bypass; $S D$, standard deviation; $D H C A$, deep hypothermic cardiopulmonary bypass; $p R B C s$, packed red blood cells. *Risk, Injury, Failure, Loss, and End-stage kidney disease. †Analysis of variance performed to test for differences among groups.

During the first 7 postoperative days, 129 patients (48\%) had an episode of AKI: 54 (20\%) had RIFLE max $_{\text {class R, } 33}$ (12\%) RIFLE $_{\max }$ class I, and $42(16 \%)$ RIFLE $_{\max }$ class F. The overall incidence of RRT was $8 \%$, and 13 of these 22 patients died. Of the 9 surviving patients with RRT, 5 recovered and no longer required dialysis, whereas 4 (1.5\% overall) left the hospital on a dialysis regimen. Nineteen (7\%) patients had postoperative CVA, and $11(4 \%)$ required reoperation during the same hospital admission. Overall, there were $36(13.4 \%)$ deaths within 30 days, which included 7 intraoperative deaths. Nineteen of the $97(19 \%)$ patients whose operations were undertaken in an emergency setting died. However, 161 patients underwent purely elective operations, and the mortality rate was $8.0 \%$ in this group. Of these patients, 122 had nonredo operations, with a $6.5 \%$ mortality rate.

Mortality rates increased with worsening severity of renal injury according to RIFLE ${ }_{\max }$ classification: 4 of 138 (3\%) RIFLE $_{\max }$ class 0,5 of 54 (9\%) RIFLE max $_{\text {max }}$ class R, 4 of $33(12 \%)$ RIFLE class I, and 16 of $42(38 \%)$ RIFLE $_{\max }$ class F patients died, respectively (Figure 1). Breakdown of patients according to RIFLE severity score and mortality data are presented in Table 4.

Logistic regression analysis identified four independent risk factors for AKI (RIFLE classes R, I, or F): hypertension $(\mathrm{OR}=2.18,95 \% \mathrm{CI} 1.14-1.48), \mathrm{pRBCs}$ greater than 5 units (OR $=2.37,95 \%$ CI 1.20-4.69), history of CKD (OR $=9.04,95 \%$ CI $1.97-41.59$ ), and ratio of admission creatinine/MDRD predicted creatinine greater than 1 (OR = $3.54,95 \%$ CI 1.95-6.45). Aprotinin was included in the statistical model and was not found to be a significant predictor for renal dysfunction; however, in this series only a minority of patients (11\%) had not received aprotinin (Table 5).

Three variables were independently associated with RRT on logistic regression analysis: history of $\mathrm{CKD}(\mathrm{OR}=4.86$, 95\% CI 1.40-16.86), pRBCs greater than 5 units (OR = $11.5,95 \%$ CI 2.73-48.41), ratio of admission creatinine/ MDRD predicted creatinine greater than $1(\mathrm{OR}=8.58$, $95 \%$ CI, 1.01-72.88). Redo surgical status $(\mathrm{OR}=0.12$, 95\% CI 0.02-0.72) was found less likely to be associated with postoperative RRT (see Table 6).

For mortality, age (per 10 years), history of CAD, hypertension, redo, emergency surgery, AKI (RIFLE classes $\mathrm{R}$, I, or F), CPB time, DHCA time, pRBCs greater than 5 units, postoperative CVA, and need for reoperation were entered into the logistic regression model. Significant predictors for in-hospital mortality were AKI (OR $=4.60,95 \%$

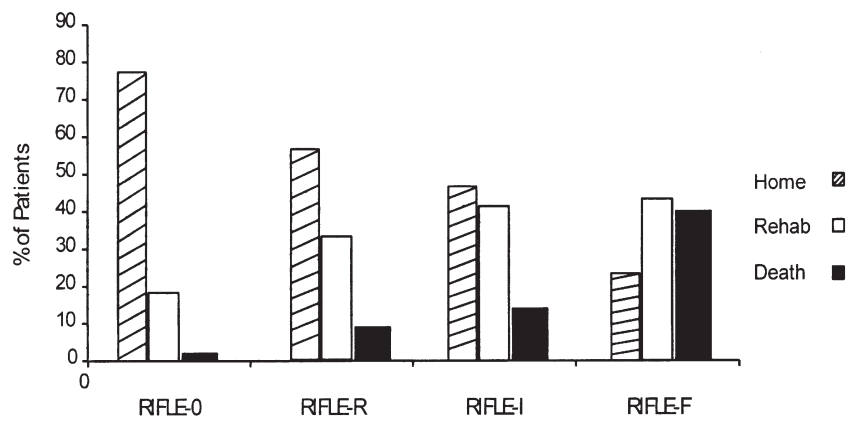

Figure 1. Final disposition according to RIFLE classification. 
TABLE 4. Group outcomes according to RIFLE* classification

\begin{tabular}{lccc}
\hline $\begin{array}{l}\text { RIFLE } \\
\text { category }\end{array}$ & No.t (\%) & $\begin{array}{c}\text { RRT No.‡ } \\
\text { (\% of RIFLE category) }\end{array}$ & $\begin{array}{c}\text { Thirty-day } \\
\text { mortality No. } \\
\text { (\% of RIFLE category) }\end{array}$ \\
\hline RIFLE-0 & $138(52 \%)$ & $0(0 \%)$ & $4(3 \%)$ \\
Risk & $54(20 \%)$ & $0(0 \%)$ & $5(9 \%)$ \\
Injury & $33(12 \%)$ & $0(0 \%)$ & $4(12 \%)$ \\
Failure & $42(16 \%)$ & $22(63.6 \%)$ & $16(38 \%)$ \\
Total & 267 & 22 & 36 \\
\hline
\end{tabular}

$R R T$, Renal replacement therapy. ${ }^{*} \mathrm{RIFLE}=$ risk, injury, failure, loss, and end-stage kidney disease. †Data were available to compute RIFLE scores for 267 patients. There were 7 intraoperative deaths, 2 CKD without AKI, and 5 chronic hemodialysis patients who were excluded from RIFLE analysis. $¥$ According to original RIFLE description, all patients with postoperative RRT classified as RIFLE-F.

CI 1.34-15.77), age per 10 years $(\mathrm{OR}=2.35,95 \% \mathrm{CI}$ $1.35-4.07)$, and postoperative CVA $(\mathrm{OR}=19.10,95 \% \mathrm{CI}$ 4.96-73.58) (see Table 2).

\section{Discussion}

Renal complications after aortic surgery are common; however, the multitude of definitions used has complicated comparison between series. ${ }^{22}$ The purpose of this report was to validate the new international consensus RIFLE classification scheme for AKI in the setting of aortic arch surgery. The RIFLE criteria were established in 2004 by the Acute Dialysis Quality Initiative, incorporating both laboratory and clinical parameters to assess renal function. A recent report used the RIFLE system in a contemporary cardiac surgery population ${ }^{17}$; however, in that series the majority of patients were at low risk for renal complications. The present study examines patients undergoing aortic arch sur-

TABLE 5. Multivariate Analysis for AKI (All RIFLE stages)

\begin{tabular}{|c|c|c|c|}
\hline Variable & $\mathbf{O R}$ & $95 \% \mathrm{CI}$ & $P$ value \\
\hline Age (per 10 y) & 1.22 & $0.96-1.55$ & .09 \\
\hline History of CAD (yes vs no) & 1.21 & $0.64-2.28$ & .55 \\
\hline Hypertension (yes vs no) & 2.18 & $1.14-4.14$ & .02 \\
\hline Redo & 1.15 & $0.53-2.50$ & .72 \\
\hline History of CKD & 9.04 & $1.97-41.59$ & $<.01$ \\
\hline $\begin{array}{l}\text { Ratio of admission } \\
\text { creatinine/MDRD predicted } \\
\text { creatinine }>1\end{array}$ & 3.54 & $1.95-6.45$ & $<.01$ \\
\hline Emergency surgery & 0.93 & $0.49-1.77$ & .84 \\
\hline CPB time $>200 \mathrm{~min}$ & 1.14 & $0.56-2.30$ & .71 \\
\hline DHCA time $>31 \mathrm{~min}$ & 1.38 & $0.70-2.72$ & .35 \\
\hline pRBCs $>5$ units & 2.37 & $1.20-4.69$ & .01 \\
\hline
\end{tabular}

$A K I$, Acute kidney injury; $O R$, odds ratio; $C l$, confidence interval; $C A D$, Coronary artery disease; $C K D$, chronic kidney disease; MDRD, Modification of Diet in Renal Disease; $C P B$, cardiopulmonary bypass; $D H C A$, deep hypothermic circulatory arrest; $p R B C s$, packed red blood cells.
TABLE 6. Multivariate analysis for RRT

\begin{tabular}{lccr}
\hline Variable & OR & 95\% Cl & $\boldsymbol{P}$ value \\
\hline Age (per 10 y) & 0.97 & $0.61-1.54$ & .90 \\
History of CAD & 0.89 & $0.24-3.24$ & .86 \\
Hypertension & 1.56 & $0.45-5.38$ & .48 \\
Redo & 0.12 & $0.02-0.72$ & .02 \\
History of CKD & 4.86 & $1.40-16.86$ & .01 \\
Ratio of admission & 8.58 & $1.01-72.88$ & .05 \\
$\quad$ creatinine/MDRD & & & \\
$\quad$ predicted creatinine $>1$ & & & .65 \\
Emergency surgery & 1.28 & $0.43-3.86$ & .77 \\
CPB time $>$ 200 min & 1.20 & $0.34-4.21$ & .24 \\
DHCA time $>$ 31 min & 2.00 & $0.62-6.39$ & $<.01$ \\
pRBCs $>$ 5 units & 11.50 & $2.73-48.41$ & \\
\hline
\end{tabular}

$R R T$, Renal replacement therapy; $O R$, odds ratio; $C l$, confidence interval; $C A D$, coronary artery disease; $C K D$, chronic kidney disease; $M D R D$, Modification of Diet in Renal Disease; $C P B$, cardiopulmonary bypass; $D H C A$, deep hypothermic circulatory arrest; $p R B C s$, packed red blood cells.

gery at high risk for renal injury and found the incidence of AKI as defined by any RIFLE category (R, I, or F) to be $48 \%$, which was over twofold greater than the earlier series. This finding is not unexpected, inasmuch as both aortic surgery and DHCA are known to be independent risk factors for renal dysfunction. ${ }^{20,23}$

The logistic regression model identified hypertension, chronic kidney disease, pRBCs greater than 5 units, and ratio admission creatinine/MDRD predicted creatinine greater than 1 as independent risk factors for renal injury, all of which are in accordance with earlier reports. ${ }^{6,19}$ Predictors for RRT also included CKD, pRBCs greater than 5 units, and ratio admission creatinine/MDRD predicted creatinine greater than 1 . Assuming a GFR between 75 and 100 $\mathrm{mL} / \mathrm{min}$, the MDRD formula can be used to predict a normal baseline creatinine. Patients whose admission creatinine was greater than MDRD predicted creatinine were at increased risk for AKI and RRT, suggesting that even subtle abnormalities in creatinine values may portend adverse outcomes with respect to renal function. Total pRBCs greater than 5 units was found by Mora Mangano and associates ${ }^{6}$ to be independently associated with renal dysfunction. In their discussion, they concluded, however, that there was no direct causality between blood transfusion and renal dysfunction; rather this finding was a reflection of hypovolemia, thought to be the cause for renal dysfunction. ${ }^{6}$ Similarly, we concur that increased total pRBCs, while used as a lifesaving measure, can be a surrogate marker for the very critically ill nature of the patients requiring such volume of blood products. However, there is evidence from a nonrandomized trial that increased RBC transfusion may worsen morbidity and mortality rates in a population of patients undergoing isolated coronary artery bypass grafting. Postulated explanations for adverse outcomes related to transfu- 
sion include proinflammatory end-organ damage and an adverse immunomodulatory effect on T-cell function. ${ }^{24}$

Interestingly, the present series found redo surgical status associated with a decreased need for postoperative RRT, which is not consistent with other large series. ${ }^{19}$ We propose the following explanation for this inconsistency. Patients in this series predominantly required the use of DHCA for one of two disease processes: (1) acute aortic dissection and (2) aneurysmal aortic disease. Patients who had redo operations were more likely to undergo elective aneurysm repair. In comparison, patients with acute aortic dissection less frequently had redo operations and more frequently were operated on in an emergency setting, occasionally in profound shock.

We found that $22(8 \%)$ patients required postoperative RRT (either hemodialysis or continuous venovenous hemofiltration), similar to other large series of patients undergoing aortic arch reconstructions. ${ }^{25-27}$ Among patients requiring RRT postoperatively, 13 (59\%) died. This figure underscores the bleak prognostic implications of RRT after cardiovascular surgery, and postoperative RRT has previously been found to independently predict mortality. ${ }^{11}$ Others have reported similar mortality rates in patients requiring RRT postoperatively, ranging from $28 \%$ in a routine coronary bypass population ${ }^{28}$ to $57 \%$ in patients undergoing DHCA for aortic arch aneurysm repair. ${ }^{27}$

AKI, advanced age, and postoperative CVA all represent an independent association with mortality in this series. Advanced age is a widely known risk factor for perioperative mortality. RRT is a documented risk factor for mortality, and in this series $8 \%$ of the patients required RRT. To avoid confounding, we included AKI but not RRT in the logistic regression model for mortality. Given the findings in this study, we conclude that even less severe renal dysfunction as defined by AKI (RIFLE classes R, I, or F) is independently associated with mortality. Considering that $48 \%$ of this cohort met criteria for AKI using the RIFLE definition, this suggests that a large number of patients in the setting of DHCA are at jeopardy for adverse outcomes including mortality. Increasing mortality was noted with progressive RIFLE class as patients with no detectable renal dysfunction (RIFLE class 0) experienced a mortality of 3\%; however, this increased proportionately in RIFLE classes $\mathrm{R}$ (9\%), I (12\%), and F (38\%), respectively. Others have documented increased mortality with increasing RIFLE classification in noncardiac surgery patients ${ }^{29}$ and in more routine cardiac surgery populations. ${ }^{17}$ We have shown a similar result in a more homogeneous population of patients, who all underwent DHCA for aortic arch repair.

The safety of aprotinin in cardiac surgery remains controversial. ${ }^{30,31}$ Aprotinin was incorporated into the logistic regression model as a variable, but no association was identified. Because a majority of patients in this series received aprotinin and only a small number did not receive it, we had low power to detect any significant effect of aprotinin in regard to renal dysfunction or mortality.

The RIFLE classification system also includes a differentiation between RIFLE outcome categories L (loss, temporary dialysis) and $\mathrm{E}$ (end-stage permanent dialysis), which were not included because this information was not available in our retrospective database. This is a limitation of the study, because it is not readily known whether these two outcomes represent a different long-term risk for mortality. In addition, it is unclear whether increasing severity of RIFLE score corresponds to a lower likelihood of recovery of renal function. Some patients whose elevation in creatinine qualifies them for AKI according to the RIFLE definition have a return to baseline on hospital discharge, whereas in others creatine levels remain slightly elevated. It is unclear whether those who only partially recover from their episode of AKI have worse long-term outcomes than do patients with complete recovery, a question that merits further study. The urine output criteria, which also can be used to calculate the RIFLE class (see Table 1), pose another difficulty with using the RIFLE system during retrospective analysis inasmuch as these data are not readily available. Future prospective studies that use the RIFLE system will be able to identify patients who meet the urine output criteria for improved RIFLE classification, as well as to identify patients with temporary (L loss) or permanent ( $\mathrm{E}$ end stage) requirements for RRT.

In summary, we found the RIFLE criteria to be a useful classification system for renal failure in patients undergoing DHCA for aortic arch surgery. Future clinical trials designed to study renal protective interventions in aortic surgery should incorporate the RIFLE criteria.

\section{References}

1. Griepp RB, Stinson EB, Hollingsworth JF, Buehler D. Prosthetic replacement of the aortic arch. J Thorac Cardiovasc Surg. 1975;70: 1051-63.

2. Estrera AL, Miller CC, 3rd, Huynh TT, Porat EE, Safi HJ. Replacement of the ascending and transverse aortic arch: determinants of long-term survival. Ann Thorac Surg. 2002;74:1058-64; discussion 1064-5.

3. Laas J, Jurmann MJ, Heinemann M, Borst HG. Advances in aortic arch surgery. Ann Thorac Surg. 1992;53:227-32.

4. Strauch JT, Spielvogel D, Lauten A Galla JD, Lansman SL, McMurtry $\mathrm{K}$, et al. Technical advances in total aortic arch replacement. Ann Thorac Surg. 2004;77:581-9; discussion 589-90.

5. Goldstein DJ, DeRosa CM, Mongero LB, Weinberg AD, Michler RE, Rose EA, et al. Safety and efficacy of aprotinin under conditions of deep hypothermia and circulatory arrest. J Thorac Cardiovasc Surg. 1995;110:1615-21; discussion 1621-2.

6. Mora Mangano CT, Neville MJ, Hsu PH, Mignea I, King J, Miller DC. Aprotinin, blood loss, and renal dysfunction in deep hypothermic circulatory arrest. Circulation 2001(12 Suppl 1);104:I276-81.

7. Augoustides JG, Floyd TF, McGarvey ML, Ochroch EA, Pochettino A, Fulford S, et al. Major clinical outcomes in adults undergoing thoracic aortic surgery requiring deep hypothermic circulatory arrest: quantification of organ-based perioperative outcome and detection of 
opportunities for perioperative intervention. J Cardiothorac Vasc Anesth. 2005;19:446-52.

8. Augoustides JG, Pochettino A, Ochroch EA, Cowie D, McGarvey ML, Weiner J, et al. Clinical predictors for prolonged intensive care unit stay in adults undergoing thoracic aortic surgery requiring deep hypothermic circulatory arrest. J Cardiothorac Vasc Anesth. 2006;20:8-13.

9. Bove T, Calabró MG, Landoni G, Aletti G, Marino G, Crescenzi G, et al. The incidence and risk of acute renal failure after cardiac surgery. J Cardiothorac Vasc Anesth. 2004;18:442-5.

10. Leacche M, Winkelmayer WC, Paul S, Lin J, Unic D, Rawn JD, et al. Predicting survival in patients requiring renal replacement therapy after cardiac surgery. Ann Thorac Surg. 2006;81:1385-92.

11. Chertow GM, Levy EM, Hammermeister KE, Grover F, Daley J. Independent association between acute renal failure and mortality following cardiac surgery. Am J Med. 1998;104: 343-8.

12. Crawford ES, Svensson LG, Coselli JS, Safi HJ, Hess KR. Surgical treatment of aneurysm and/or dissection of the ascending aorta, transverse aortic arch, and ascending aorta and transverse aortic arch: factors influencing survival in 717 patients. J Thorac Cardiovasc Surg. 1989;98:659-73; discussion 673-4

13. Sundt TM 3rd, Kouchoukos NT, Saffitz JE, Murphy SF, Wareing TH, Stahl DJ. Renal dysfunction and intravascular coagulation with aprotinin and hypothermic circulatory arrest. Ann Thorac Surg. 1993;55: 1418-24.

14. Hoste EA, Clermont G, Kersten A, Venkataraman R, Angus DC, De Bacquer D, et al. RIFLE criteria for acute kidney injury are associated with hospital mortality in critically ill patients: a cohort analysis. Crit Care. 2006;10:R73.

15. Eaton MP, Deeb GM. Aprotinin versus epsilon-aminocaproic acid for aortic surgery using deep hypothermic circulatory arrest. J Cardiothorac Vasc Anesth. 1998;12:548-52.

16. Bellomo R, Ronco C, Kellum JA, Mehta RL, Palevsky P; Acute Dialysis Quality Initiative workgroup. Acute renal failure-definition, outcome measures, animal models, fluid therapy and information technology needs: the Second International Consensus Conference of the Acute Dialysis Quality Initiative (ADQI) Group. Crit Care. 2004;8: R204-212

17. Kuitunen A, Vento A, Suojaranta-Ylinen R, Pettila V. Acute renal failure after cardiac surgery: evaluation of the RIFLE classification. Ann Thorac Surg. 2006;81:542-6.

18. K/DOQI clinical practice guidelines for chronic kidney disease: evaluation, classification, and stratification. Am J Kidney Dis. 2002;39:S1266.

19. Chertow GM, Lazarus JM, Christiansen CL, Cook EF, Hammermeister KE, Grover F, et al. Preoperative renal risk stratification. Circulation. 1997;95:878-84

20. Zanardo G, Michielon P, Paccagnella A, Rosi P, Caló M, Salandin V, et al. Acute renal failure in the patient undergoing cardiac operation: prevalence, mortality rate, and main risk factors. J Thorac Cardiovasc Surg. 1994;107:1489-95.

21. Stevens LA, Coresh J, Greene T, Levey AS. Assessing kidney function-measured and estimated glomerular filtration rate. $N$ Engl J Med. 2006;354:2473-83.

22. Augoustides JG, Pochettino A, Ochroch EA, Cowie D, Weiner J, Gambone AJ, et al. Renal dysfunction after thoracic aortic surgery requiring deep hypothermic circulatory arrest: definition, incidence, and clinical predictors. J Cardiothorac Vasc Anesth. 2006;20:673-7.

23. Gaudino M, Luciani N, Giungi S, Caradonna E, Nasso G, Schiavello $\mathrm{R}$, et al. Different profiles of patients who require dialysis after cardiac surgery. Ann Thorac Surg. 2005;79:825-9; author reply 829-30.

24. Koch CG, Li L, Duncan AI, Mihaljevic T, Cosgrove DM, Loop FD, et al. Morbidity and mortality risk associated with red blood cell and blood-component transfusion in isolated coronary artery bypass grafting. Crit Care Med. 2006;34:1608-16.

25. Svensson LG, Crawford ES, Hess KR, Coselli JS, Safi HJ. Experience with 1509 patients undergoing thoracoabdominal aortic operations. $J$ Vasc Surg. 1993;17:357-68; discussion 368-70.

26. Gummert JF, Bucerius J, Walther T, Doll N, Falk V, Schmitt DV, et al. Requirement for renal replacement therapy in patients undergoing cardiac surgery. Thorac Cardiovasc Surg. 2004;52:70-6.
27. Patel HJ, Shillingford MS, Mihalik S, Proctor MC, Deeb GM. Resection of the descending thoracic aorta: outcomes after use of hypothermic circulatory arrest. Ann Thorac Surg. 2006;82:90-5; discussion 95-6.

28. Conlon PJ, Stafford-Smith M, White WD, Newman MF, King S, Winn MP, et al. Acute renal failure following cardiac surgery. Nephrol Dial Transplant. 1999;14:1158-62.

29. Bell M, Liljestam E, Granath F, Fryckstedt J, Ekbom A, Martling CR. Optimal follow-up time after continuous renal replacement therapy in actual renal failure patients stratified with the RIFLE criteria. Nephrol Dial Transplant. 2005;20:354-60.

30. Mangano DT, Tudor IC, Dietzel C. The risk associated with aprotinin in cardiac surgery. $N$ Engl J Med. 2006;354:353-65.

31. Mangano DT, Miao Y, Vuylsteke A, Tudor IC, Juneja R, Filipescu D, et al. Mortality associated with aprotinin during 5 years following coronary artery bypass graft surgery. JAMA. 2007;297:471-9.

\section{Discussion}

Dr R. Scott Mitchell (Stanford, Calif). Dr Arnaoutakis, you and your colleagues are to be complimented for an excellent report.

Your study embracing the relatively new RIFLE classification introduces a very desirable standardization with three grades of renal injury-risk, injury, and failure-in increasing severity. These grades of severity are based exclusively on postoperative changes in plasma creatinine, GFR, or urinary output. Its strengths are the ability to compare apples with apples, which we desperately need as we manipulate postoperative variables. This is a much needed standardization.

Its weakness, to my eye, however, is that it really is predictive of only things after the surgical event, which is the one time where we may most capably modulate the renal injury. Certainly intraoperative variables may be very important to postoperative patient performance. I wonder whether you might have included in your variables such things as perfusion strategies, antegrade versus retrograde perfusion through axillary arteries or femoral cannulation, or whether you looked at the effect of temperatures, since temperature and bypass times may be correlated.

Would you agree that more intraoperative variables might be introduced into this model so that you can be more predictive? Second, do you think the actual protective effect that you saw for the reoperative patients was due, as you suggested, to the decreased incidence of emergency operations in that patient cohort or to some other effect?

Dr Arnaoutakis. Thank you, Dr. Mitchell, for your excellent points and questions. I should echo the points that you made that this system is not instated to be a predictive tool, but rather a classification system, such that in future studies we would be comparing apples with apples. The hope is to disseminate a widespread nomenclature that we can use when discussing renal failure.

With respect to your questions regarding variables, in our early experience most patients were cannulated by the femoral artery; however, recently we have adopted selective use of axillary cannulation and we do have plans to review these data and perhaps incorporate them into some of our models.

With respect to your second question concerning the redo, this was a curious finding to us as well. Patients in this series were homogeneous in that all required use of circulatory arrest; however, they were operated on primarily for one of two diseases: aortic aneurysms or acute aortic dissections. In looking back at the data, because of this peculiar finding, we found that nearly $90 \%$ of the redo operations were in an elective setting for aneurysmal 
disease and most of the acute aortic dissections were first-time operations and occasionally undertaken in the setting of profound systemic shock.

Dr Gary H. Dworkin (Clearwater, Fla). With regard to Dr Mitchell's suggestion of intraoperative variables, did you appreciate any changes or look at the use of aprotinin or other antifibrinolytics and relate them to your postoperative outcomes?

Dr Arnaoutakis. Thank you, Dr Dworkin, for your question as well. We are eminently aware of the ongoing debate regard- ing aprotinin. As a matter of fact, we did look at aprotinin. In our early experience, some patients did receive epsilon aminocaproic acid; however, in this series, the majority of patients, nearly $90 \%$, had received aprotinin. We did look at it in the model and it did not come out to be significant for any of the outcomes we looked at. However, we concluded that since there was such a disparity in the number of patients who received aprotinin versus epsilon aminocaproic acid, we had low power to detect any significant differences.

\section{Interactive eLearning Activities http://learning.ctsnet.org}

The Joint Council on Thoracic Surgery Education was pleased to introduce a series of unique eLearning activities to CTSNet users at the AATS annual meeting in Philadelphia. Sponsored by several cardiothoracic surgical groups, this exciting new educational tool contains narrated videos of actual surgical procedures followed by a series of questions and an evaluation to earn Continuing Medical Education credit.

* Diagnosis and Management of Complications of Mitral Valve Repair

* Off Pump Coronary Artery Bypass

* OPCAB Debriefing

* Pediatric Cardiopulmonary Bypass Emergency Situations

\section{Experience these new educational tools today and provide us with your feedback. Go to: http://learning.ctsnet.org}

William E. Baumgartner, Chair

Joint Council on Thoracic Surgery Education

Sponsored By:

American Association for Thoracic Surgery

The Society of Thoracic Surgeons

European Association for Cardio-Thoracic Surgery

Children's Memorial Hospital 